\title{
Characterization of a polypropylene fibered cement composite using ESEM, FESEM and mechanical testing
}

\author{
A. García Santos ${ }^{\text {a }}$ J.Ma. Rincón ${ }^{\mathrm{b}}$, M. Romero ${ }^{\mathrm{b}}$, R. Talero ${ }^{\mathrm{c}}$ \\ a Department of Construction and Architectural Technology, Superior Technical School of \\ Architecture, Polytechnic University of Madrid, Madrid, Spain \\ ${ }^{\mathrm{b}}$ The Glass and Ceramics Group/Lab, Instituto E. Torroja de CC. Construcción, CSIC, Madrid, Spain \\ ${ }^{\mathrm{c}}$ Department of Synthetics, Characterization, and Stability of Materials, Instituo E. Torroja de CC. \\ Construcción, CSIC, Madrid, Spain
}

Keywords: Reinforced cement mortar; Polypropylene fibres; Scanning electron microscopy

\begin{abstract}
The microstructure characterization and mechanical properties of a reinforced cement by the introduction of polypropylene fibres creating a composite material with a reduction of the weight and possible regulation of the times of setting has been carried out. A detailed microstructure determination has been made first time by environmental scanning electron microscopy and field emission scanning electron microscopy. The final surface of this composite after setting is different according to the contacts areas of mold, while the bulk microstructure is very homogeneous, depicting uniform distribution of fibres into the matrix.
\end{abstract}




\section{Introduction}

Growing of crystals from ionic solutions such as available in the cement phases are affected by the presence of heterogeneous phases as is the case of the fibre/cement matrix composites [1]. The combined behaviour between fibres and cement matrices is compatible, acting as secondary connections between the fibres and cement components. The adhesion force of cement composite materials is reached from the forces due to the secondary connections and to the mechanical entwining among the fibres [2] and [3]. Polar forces of electrostatic type can settle between the matrix and the siliceous aggregates, while a secondary action is due to the friction or physical connection favoured by irregularities of the contact surfaces [4]. Thus, the reinforcement of a composite material can be achieved by means of the following methods: (a) increase of the contact surface of the crystalline siliceous aggregates from the cement when decreasing the internal porosity, bearing an increase of the mechanical strength as well as a weight increase and (b) by addition of fibres to facilitate the absorption of internal tensions in the bending strength for the fibres and compressive strength for the cement matrix [5], [6], [7] and [8]. It is possible to use both methods simultaneously to obtain better results. The main aim of this investigation is the use of the second method, trying simultaneously to reduce the weight of this composite material [9]. Moreover, this investigation pretends also to carry out the microstructure of the material formulation obtained by embedding polypropylene fibres into a cement matrix by using the recent improved environmental and field emission scanning electron microscopies (ESEM and FESEM, respectively).

\section{Materials and experimental methods}

\section{Materials}

As matrix for the composite here investigated was used a CEM-II-32.5 B cement. According to the Spanish Cement Standards UNE 80301 [10] and the UNE-ENV 197-1 IN [11] the matrix of the composite was prepared from a Portland clinker cement (68\%); natural puzolane $(20 \%)$; limestone $(12 \%)$ and sulfates $(3.07 \%)$ and without chlorides. Fibres introduced into the matrix were polypropylene (FPP) ribbons of rectangular section with average size $150 \times 25 \mu \mathrm{m}$ with average lengths of $20 \mathrm{~mm}$. 


\section{Mix proportions, processing and curing}

Melamine formaldehyde dispersion (MF) (Melment F-10) was used to reduce the mixing water. This is a synthetic product which allows the reduction of the quantity of water in the mixture, maintaining the plasticity for moulding [12]. The processing of specimens has been carried out according to the Spanish Standard EN 83502-88 for testing of concrete and mortars [13] established for the preparation of this type of composites in the laboratory, being used a mechanical molding and compacting with 60 shots/min during mixing of fibres. The synthetic fibres were added in percentages from 0.1 to 3.0 wt.\%, while the cement mortar was mixed into a mechanical rotula-turbo mixer. The MF additive was added in $0.5 \mathrm{wt} . \%$ and the manufactured specimens were stored in humid cabinet at relative humidity higher than $60 \%$ during $48 \mathrm{~h}$. The ratio cement/aggregate/water was of $1 / 3 / 0.5$ with $\mathrm{pH}=7$ for water and curing times of 7 and 28 days.

\section{Mechanical testing (compressive and tensile properties)}

The mechanical strengths were determined according to the UNE EN-196-1 European and Spanish Standard included in [13]. The mechanical properties measured have been the flexural and compressive strengths by mean of specimens $(40 \times 40 \times 160 \mathrm{~mm})$ of standard cement mortar type. Moreover, different percentages of FPP have been added $(0.1,0.25,0.5,0.75,1.00,1.5,2.00,2.5$ and 3.00 wt.\%), obtaining those denominated single additions. Other samples with additions were also prepared with the former percentages of fibres and with additional inclusion of $0.5 \mathrm{wt} \%$ of MF (Melment F-10).

\section{Microstructure observed under electron microscopy}

Detailed microstructure observations have been done on a representative prismatic test specimen of $16 \times 3 \times 3 \mathrm{~cm}^{3}$ named: $25-115-3$ (sample with $2 \%$ fibres plus $0.5 \%$ MF and 28 days aging) which was previously tested to bending rupture, in which were seen at first sight bundles of polymeric fibres on its surface. On the fracture surface resulting from the fracture testing are also visible beams of polymeric fibres stuffed in the matrix cement.

In recent years the electron microscopy has demonstrated to be a very valuable method for determination of microstructure on inorganic materials [14] and [15]. Therefore, the observation of 
fractured as well as the pristine surfaces of composite here investigated can give information about phases (matrix and fibered dispersed) which constitute this material. Fig. 1 shows a drawing of the composite specimen where the detailed microstructure investigation was carried out depicting the several surface areas observed by several methods of scanning electron microscopy. The area A corresponds to a removed sheet layer of the superior surface (compression zone); area B corresponds to the fracture surface produced as a consequence of the break after the flexural tests showing the edges of fibres; area $\mathrm{C}$ corresponds to a relatively smooth surface in contact with the mold; area D corresponds to an inferior area (tensile zone) that appears lifted or swollen; area $\mathrm{E}$ is an interface area of an almost cubic type break block produced along the test specimen by shear effect in this area and, finally, it has been observed an area (not shown in Fig. 1) from a transversal section produced by a diamond cutter which has been used to prepare and give the samples the adequate size to be observed to higher magnifications.

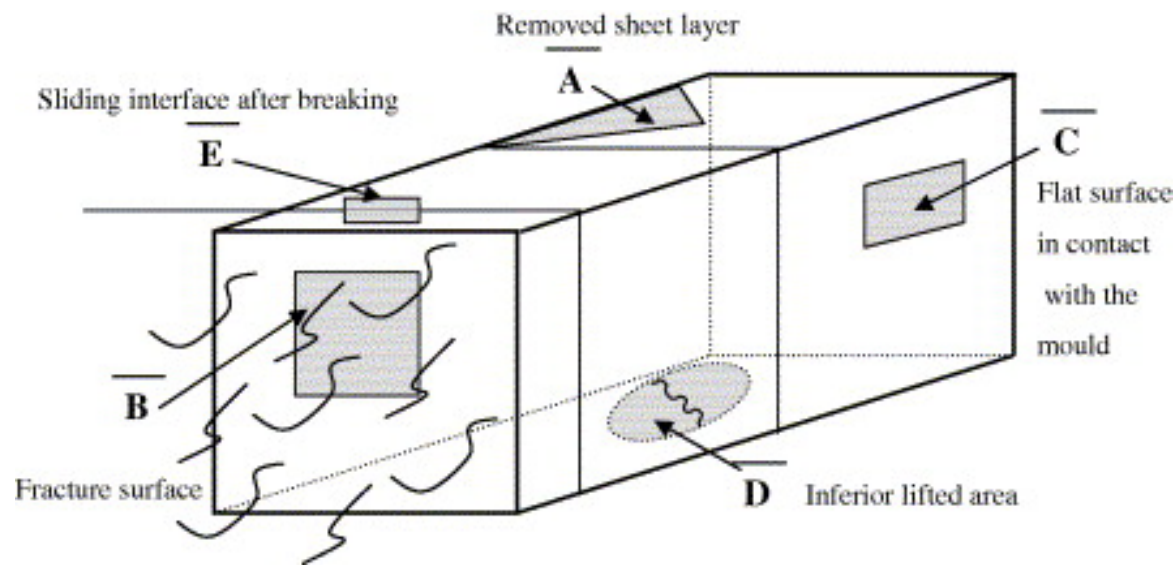

Fig. 1. Areas from the specimen of polypropylene/cement composite where the electron microscopy observations were carried out.

The microstructure observation has been carried out with a field emission scanning electron microscope (FESEM) Hitachi S-4100 working to $5 \mathrm{kV}$ which allows the observation with more resolution than conventional scanning electron microscope (SEM) [16]. This observation has been complemented with other carried out under environmental scanning electron microscopy (ESEM) by using a Philips XL-30 instrument equipped with EDX spectrometer. Because of this composite is nonconductive and crystalline phases contain water, the conventional high vacuum SEM observations require specific preparation methods by: (a) removing of water by freezing of process and (b) metal coating by sputtering of samples. Thus, the images in those cases represents a frozen state and not a real case, while the ESEM allows the observation of samples with different content of water phase 
without inherent damage and conduction problems coming from electron irradiation or lack of conductivity. The imaging from secondary electrons in this case is possible due to a gas secondary electron detector (GSE) working in water pressure of 2.0 Torr and was used at $20 \mathrm{kV}$ acceleration voltage, $20 \mathrm{~mA}$ current intensity [17]. In order to facilitate the observations under FESEM microscope, the composite samples were previously cut and covered with a thin evaporated gold layer by Sputtering using Balzers equipment with evaporation time of $90 \mathrm{~s}$.

\section{Results and discussion}

\section{Mechanical properties}

The bending and compression strength results have been represented in Fig. 2 and Fig. 3 from data of samples with 7 and 28 days aging for cement reinforced with polypropylene and cement reinforced with polypropylene and melamine formaldehyde dispersion agent as additive.

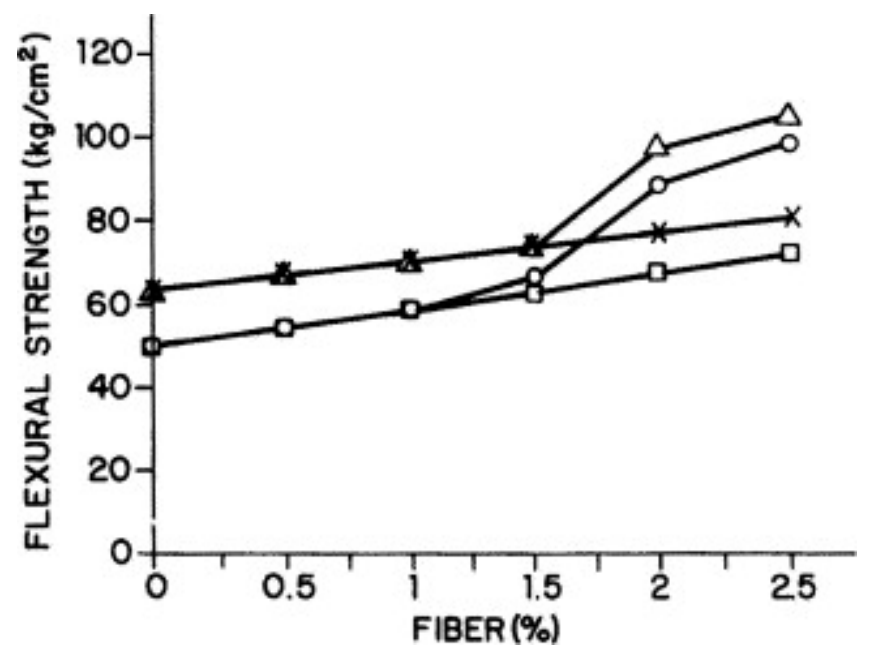

Fig. 2. Behaviour to flexural strength of cement matrix reinforced with polypropylene (symbol $\square: 7$ days setting and $\times: 28$ days setting, respectively) and with additive of polypropylene with melamine formaldehyde $(0.5 \%)$ (symbol $\circ: 7$ days and ${ }^{\Delta}: 28$ days curing time, respectively). 


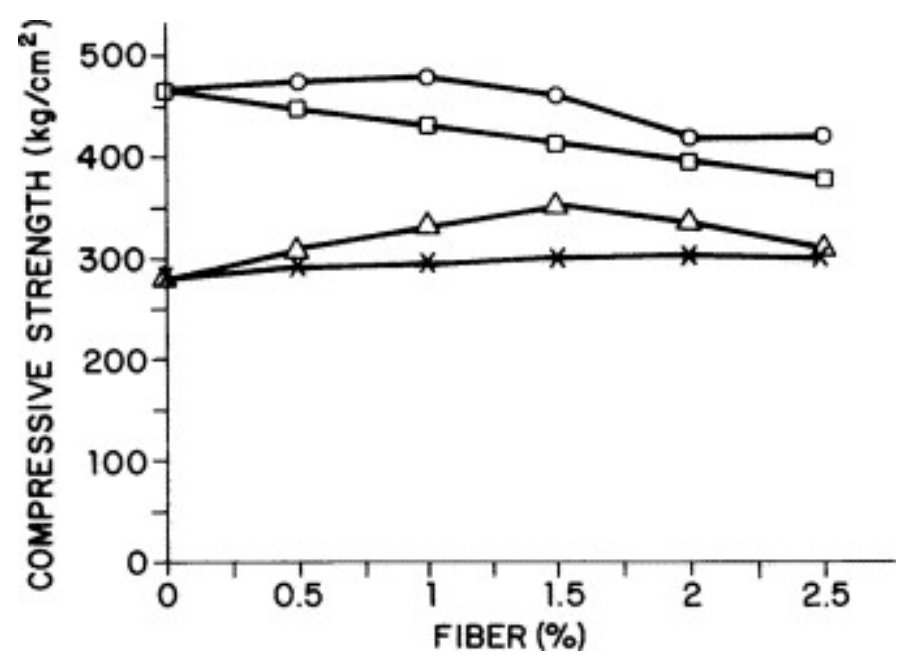

Fig. 3. Behaviour to compressive strength of cement matrix reinforced with polypropylene (symbol $\times$ : 7 days setting and $\square: 28$ days setting, respectively) and with additive of polypropylene with melamine formaldehyde $(0.5 \%)$ (symbol $\triangle: 7$ days and $\circ: 28$ days curing time, respectively).

a) Bending strength of cement composite reinforced with polypropylene and with polypropylene and melamine formaldehyde ( $0.5 \%)$, ages: 7 and 28 days.

The values of flexural mechanical strength of this cement composite increase in connection with the increase of the percentage of addition of the fibre. It was observed an increase of flexural strength in the binary samples with respect the unitary samples by the addition of $1.5 \mathrm{wt} . \%$ of fibres, as well as an increment in aged samples between 7 and the 28 days (Fig. 2). The relative quantitative increments of this mechanical property can be seen in Table 1 .

Table 1. Relative resistance increment of bending or flexural strength with respect the reference sample of cement mortar reinforced with variable percentages of polypropylene fibre (FPP) additions, melamine formaldehyde (MF) $(0.5 \%)$ and with polypropylene with melamine formaldehyde $(0.5 \%)^{\mathrm{a}}$

\begin{tabular}{lcrrrrr}
\hline Addition type & Days (aging) & \multicolumn{5}{c}{ FPP addition (wt.\%) } \\
\hline & & 0.5 & 1 & 1.5 & 2 & 2.5 \\
\cline { 3 - 7 } Single addition & 7 & 8.9 & 17.91 & 26.86 & 35.82 & 44.78 \\
Single addition & 28 & 5.19 & 10.38 & 15.58 & 20.77 & 25.96 \\
$+0.5 \% \mathrm{MF}$ & 7 & 8.9 & 17.91 & 33.83 & 77.61 & 97.51 \\
$+0.5 \% \mathrm{MF}$ & 28 & 5.19 & 10.38 & 15.53 & 54.09 & 64.89 \\
\hline
\end{tabular}

Aging: 7 and 28 days.*FPP: fibres of $20 \mathrm{~mm}$ of average length.

${ }^{\text {a }}$ Bending strength $\Delta \sigma f(\mathrm{~kg} / \mathrm{cm} 2) \pm 0.10$. 
(b) Compressive strength of cement composite reinforced with polypropylene and with polypropylene and melamine formaldehyde (0.5\%): 7 and 28 days aging.

In Fig. 3, the variation of compressive strength for 7 and 28 days aging, which lightly decrease with the fibre addition is shown. Similarly, the binary additions of polypropylene fibres and MF produces simultaneous and favouring effects with regard to the single additions of fibres, improving the mechanical properties with respect the unitary additions. Table 2 gives the relative variation of compressive strength values for the unitary and binary additions. In this case an increase of compressive strength with increased additions of FPP fibres produces progressive enhancements of the compressive strength with 7 days of curing time, being higher this increase with the addition of $0.5 \%$ of MF. However, with 28 days of curing time there is a decrease of this mechanical property. Only with the addition of 1 wt. $\%$ of fibres and $0.5 \%$ of MF is maintained the value of the compressive strength of this composite material.

Table 2. Relative resistance increment of compressive strength with respect the reference sample of cement mortar reference sample and those reinforced with variable percentages of polypropylene fibre (FPP) additions, melamine formaldehyde (MF) $(0.5 \%)$ and with polypropylene with melamine formaldehyde $(0.5 \%)^{\mathrm{a}}$

\begin{tabular}{lcrrrrr}
\hline Addition type & Days (aging) & \multicolumn{5}{c}{ FPP addition (wt.\%) } \\
\hline & & 0.5 & 1 & 1.5 & 2 & 2.5 \\
\cline { 3 - 7 } Single addition & 7 & 3 & 3.76 & 7.82 & 10.43 & 7.38 \\
Single addition & 28 & -4.00 & -7.42 & -11.13 & -14.89 & -18.59 \\
$+0.5 \% \mathrm{MF}$ & 7 & 10.7 & 18.53 & 26.01 & 21.88 & 11.51 \\
$+0.5 \% \mathrm{MF}$ & 28 & 1.91 & 2.79 & -1.12 & -9.74 & -9.45 \\
\hline
\end{tabular}

Aging: 7 and 28 days. ${ }^{*}$ FPP: fibres of $20 \mathrm{~mm}$ of average length.

${ }^{\text {a }}$ Bending strength $\Delta \sigma f(\mathrm{~kg} / \mathrm{cm} 2) \pm 0.10$.

\section{Analysis of the fracture lines}

The external aspect of the test specimen has been examined by direct observation of crack lines. The fracture lines were analyzed by considering their percentage, shape and distribution [18]. From cement test specimen and composite prepared with binary addition of fibre and polymeric dispersion, only one main line of rupture is observed in the central area of the test specimen. The fracture of specimen 
starts from the tensile face of the test, being reflected toward the central area into the tensile face and ascending through for the lateral ones. The good adherence between the matrix and the fibre dispersed phase is the responsible of the improvement of bending strength also giving rise to the pull-out of fibres from the matrix.

\section{Microstructure characterization by electron microscopy (ESEM and FESEM)}

The microstructure has been observed at higher magnification through recent methods of scanning electron microscopy, such as FESEM and ESEM. Fig. 4 shows some of the most representative observations from the areas obtained by ESEM microscopy (figures (a) and (b)) from the D area of Fig. 1 which correspond to the tensile zone and FESEM microscopy from the A area (compression superior zone) respectively (Fig. 4(c) and (d)) and from the C area (Fig. 4(e) and (f)) of the contact zone with mold from the same Fig. 1. Fig. 5(a)-(d) depicts several representative images which correspond to the fractured area B from Fig. 1 obtained after flexural rupture of the sample and which it was observed by FESEM microscopy.

The presence of the phases contained in the cement matrix are evident from the observation of Fig. 4(a). These are: portlandite, calcium aluminate hydrates, calcium silicate hydrates $\left(x \mathrm{CaO} \cdot y \mathrm{SiO}_{2} \cdot \mathrm{mH}_{2} \mathrm{O}\right.$ gel, which usually is written as $\left.\mathrm{C}-\mathrm{S}-\mathrm{H}[19]\right)$ and a small quantity of ettringite $\left(6 \mathrm{CaO} \cdot \mathrm{Al}_{2} \mathrm{O}_{3} \cdot 3 \mathrm{SiO}_{2} \cdot 32 \mathrm{H}_{2} \mathrm{O}\right.$, also named in the literature usually with the abbreviation: $\mathrm{AF}_{\mathrm{t}}{ }^{19}$ and as is shown in Fig. 4(a)). Also it can be seen more or less amorphous areas containing very fine acicular crystallites of about 3-7 $\mu \mathrm{m}$ length by $0.5 \mu \mathrm{m}$ width, which can be ettringite (Fig. 5(c)). In the micrograph of Fig. 5(b) very small crystallites with white contrasts are observed precipitated at the surface of fibres, indicating the nucleation of these crystallites from the interface of fibers what can favour the improved properties of this composite. $\mathrm{C}-\mathrm{S}-\mathrm{H}$ grains of gels also appear in the interface of fibres and among the fibres the presence of more or less irregular crystals are also detected. SEM/EDX microanalysis were carried out in these phases as was showed previously by Rincon et al. [20]. These microanalysis have shown that $\mathrm{S}-\mathrm{C}-\mathrm{H}$ gel is very heterogeneous with a wide range of in composition in different areas of the specimen. Thus this amorphous gel is (wt.\%): 40-48 $\mathrm{SiO}_{2} \cdot 20-42 \mathrm{CaO} \cdot 5-$ $13 \mathrm{Al}_{2} \mathrm{O}_{3} \cdot 2-9 \mathrm{MgO} \cdot 2-5 \mathrm{Na}_{2} \mathrm{O} \cdot 5-6 \mathrm{~K}_{2} \mathrm{O} \cdot 4.8-5.1 \mathrm{Fe}_{2} \mathrm{O}_{3}$, with a $\mathrm{CaO} / \mathrm{SiO}_{2}$ ratio of $0.5-0.9$ [20]. In other areas, not shown here, bundles of planed fibres absorbed in the matrix can be observed distributed homogeneously. The matrix intersects this fibre edge and shows several cracked lines which can be a consequence of the stress level that the matrix supports by the effect of the dispersed fibrous phase. The border of another fibre at diverse magnification showed the roughness of these 
fibres which are produced by a alteration phenomenon or by precipitation/nucleation of clustered crystallites of the main cement matrix (Fig. 4(e)). As is shown in the micrograph from Fig. 4(f) which corresponds to the flat face area in contact with the mold, rounded grains shaped as a "mosaic" with sizes between 20 and $50 \mu \mathrm{m}$ have been observed which is different in microstructure of other areas here investigated. As is well known, in the contact mold area is formed a thin layer of humidity where the retention of water gives rise to a thin layer of calcium enrichment producing $\mathrm{CaCO}_{3}$ in the surface which correspond to the "rounded mosaic grains" observed by FESEM microscopy [20].

Fig. 5(a)-(d) corresponds to micrographs taken from the B fracture surface shown in Fig. 1, where the fibres emerge from the matrix allowing the best observation of the cohesion degree between the dispersed phase and the cement matrix. It can be seen how a fibre penetrates or punctures the matrix into its end and the extension of the same fibre, while it can be seen clearly bent (Fig. 5(a)). The surface of the bent fibre is observed with more detail at greater magnification (Fig. 5(b)) showing crystallization (possibly of calcium aluminate hydrates by their texture and size) which covers the fibre over its surface. Agglomerated crystallites are clearly observed along the interface of fibres to the right and to the left. In some areas it seems to be that these crystallites are formed on the surface of fibres. Fig. 5(c) shows a different area from the same fracture surface depicting acicular ettringite crystals, precipitated among the fibres being detected in small proportion into the bulk of specimen. The end of a fibre with its surface curved is very clear containing numerous irregular crystallites with sizes among 5-10 $\mu \mathrm{m}$ which could be glued to the surface of this fibre or could have been formed between the fibre/matrix interface. Finally, a fibre acting as "bridge" or "anchorage" between the grains of the matrix is shown in Fig. 5(d). This micrograph is an evidence of the reinforcement effect that dispersion of polymeric fibres produces in the matrix of the composite material, which has been mentioned above to be proved with measurements of the bending strength [18]. 


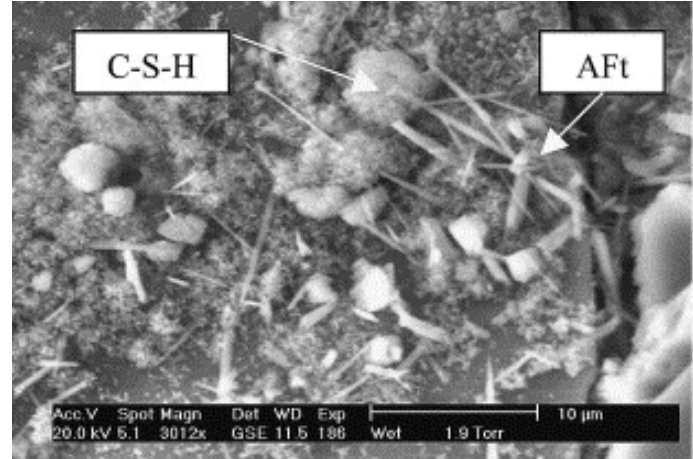

(a)

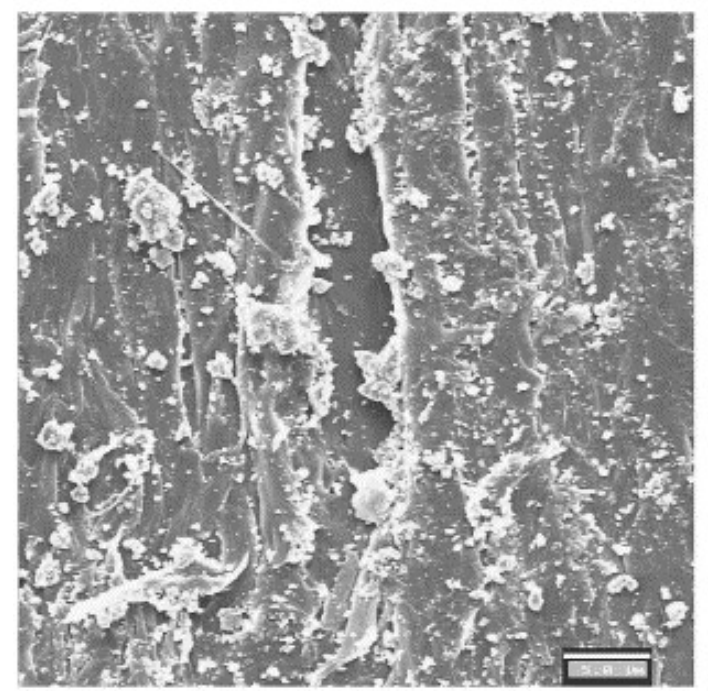

(c)

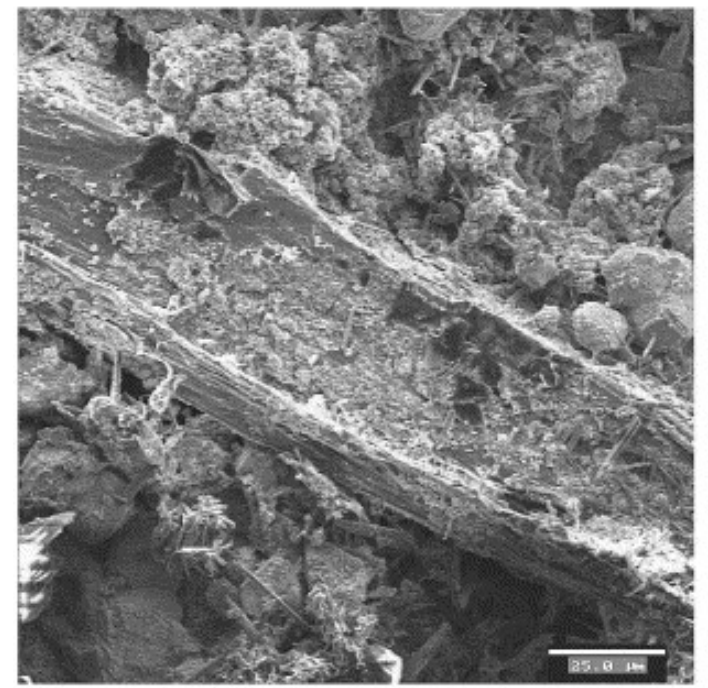

(e)

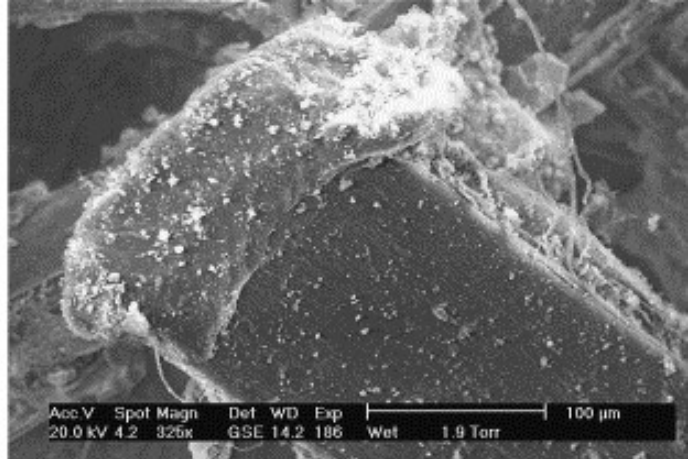

(b)

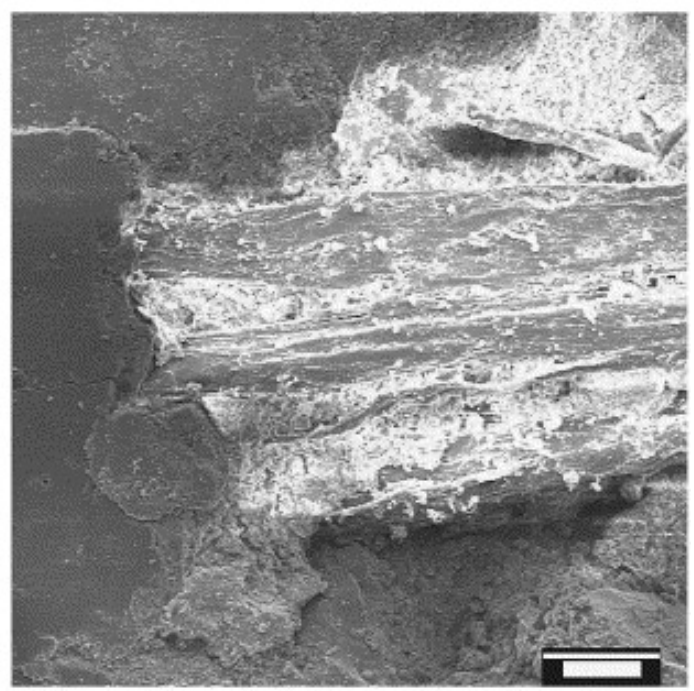

(d)

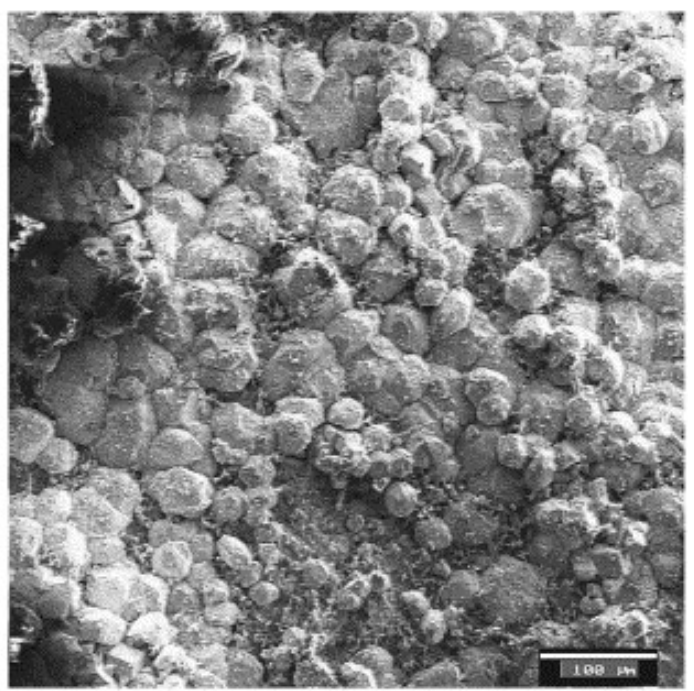

(f)

Fig. 4. Scanning electron micrographs (ESEM) at several magnifications from the representative specimen of polypropylene composite: $(a, b)$ tensile zone (D area from Fig. 1) at $3012 \times$ and $325 \times$ magnification, respectively; (c, d) compression superior zone (A area from Fig. 1) at $1800 \times$ and $480 \times$, respectively and (e, f) area in contact zone with mold at $480 \times$ and $120 \times$ magnification, respectively. 
A. García Santos, J.Ma. Rincón, M. Romero, R. Talero. Characterization of a polypropylene fibered cement composite using ESEM, FESEM and mechanical testing

Construction and Building Materials, 19 (2005) 5, 396-403; DOI: 10.1016/j.conbuildmat.2004.07.023

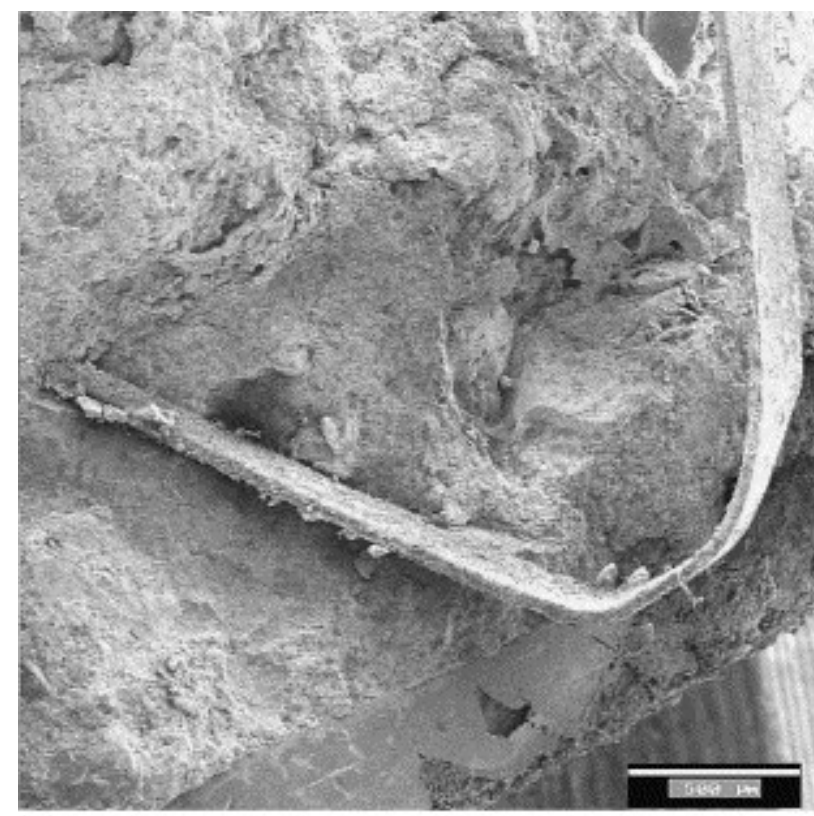

(a)

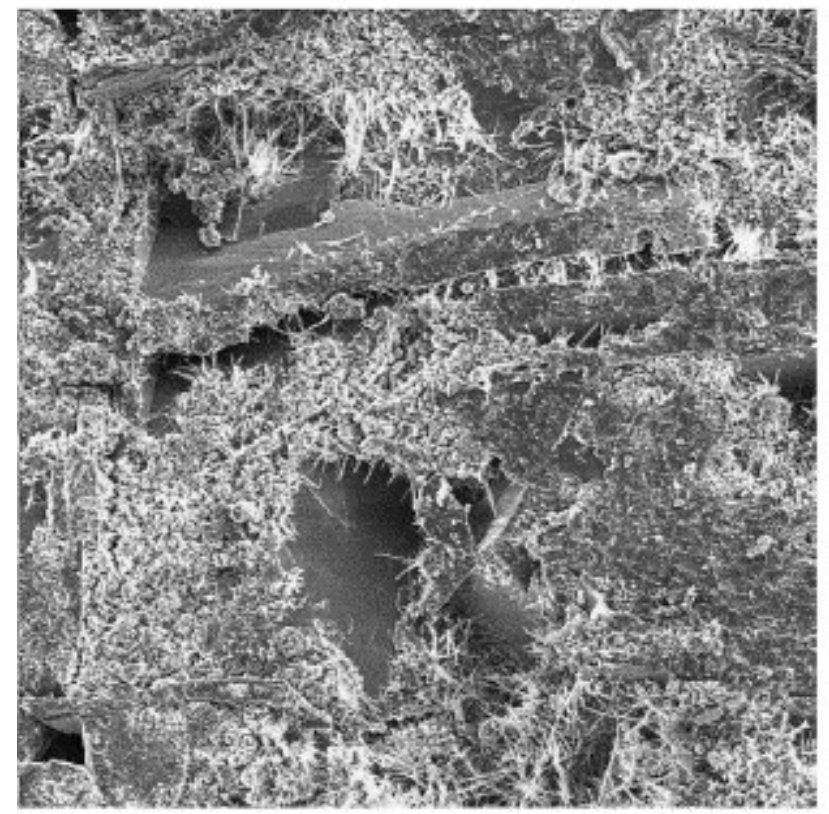

(c)

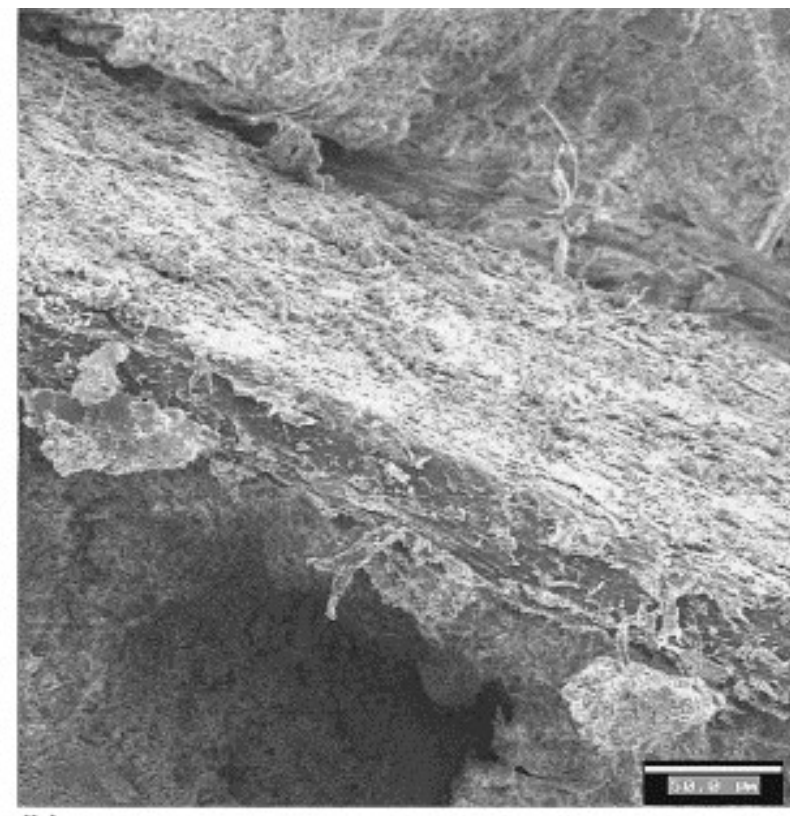

(b)

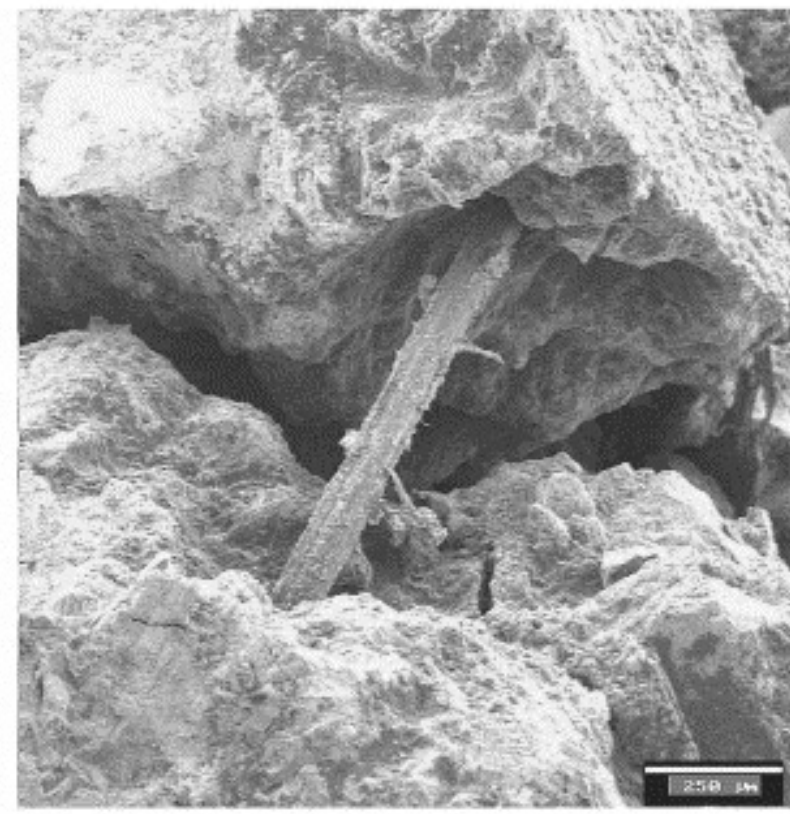

(d)

Fig. 5. Field emission scanning electron micrographs (FESEM) at several magnifications from the fracture zone (B area from Fig. 1): (a-c) fracture surface at $31 \times, 260 \times$ and $3000 \times$ magnification, respectively and (d) from an area of the cut diamond section at $50 \times$ magnification. 


\section{Conclusions}

From the testing of mechanical properties of a fibered polypropylene/cement composite with addition of MF it can be concluded that single addition of synthetic fibres of polypropylene as element of reinforcement of the cement matrix produces an increment of the bending mechanical resistance in the face of tensions according to the percentage of fibre addition. This improvement in strength is higher with the addition of MF than those obtained with only the additions of fibres in the cement matrix.

With respect to the compression strength the addition of synthetic fibres of polypropylene as element of reinforcement of the cement matrix, produces a decrease of mechanical resistance in the face of compressive strength, being similar for samples with and without additions of MF in a directly proportional way to the percentage of fibre addition. From the analysis of the mechanical behaviour, it is considered suitable the proportion of single addition of $2.0 \%$ of fibre of polypropylene giving the best values simultaneously for the bending and the compressive strength. With the addition of $0.5 \%$ of MF the optimum percentage of fibre addition for both mechanical properties is the $1 \%$ of FPP fibres.

The detailed microstructure observation of a polypropylene fibre/cement matrix composite material has been carried out with the use of ESEM and FESEM. Both methods have demonstrated to be very useful for the observation of this type of material (organic fibre compounds with presence of water in the cement phase), since they allow observation without necessity of freezing the water phase from the matrix. There were no strange effects or artifacts which are usual in other types of electron microscopy methods during the observation of cement type materials. A high degree of compatibility has been observed between the polypropylene fibres and the mentioned matrix with precipitation of crystallites over the fibres surface.

\section{Acknowledgement}

This research has been carried out thanks to the Research Project Nr. A-9907, Madrid Polytechnic University, as well as the Frame Cooperation Agreement between the Madrid Polytechnic University (UPM) and Consejo Superior de Investigations Científicas (CSIC). The facilities given by the Servei of Electron Microscopy of the University of Valencia, Burjasot Campus, for the access and direct use of the FESEM and ESEM microscopes are very appreciated. Valuable comments from Drs. $\mathrm{M}^{\mathrm{a}}$. Soledad Hernández-Crespo and $\mathrm{M}^{\mathrm{a}}$. Isabel Sanchez-Rojas from the IETcc, CSIC are also recognized. 


\section{References}

[1] P.H. Egli, L.R. Johnson. J.J. Gilman (Ed.), The art and science of growing crystals, Wiley, New York (1963), p. 194

[2] Gunn DJ. Mechanism for the formation and growth of ionic precipitates from aqueous solution, 1976. p. $133-40$

[3] R.W. Gurney. Ionic processes in solution. McGraw Hill, New York (1953)

[4] J.L. Moillet, B. Collie, W. Black. Surface activity. E and FN Spon, London (1961)

[5] H. Krenchel. Fibre reinforcement, Akademisk Forlag, Copenhagen (1964) pp. 159

[6] B.A. Sanders. Short fibre reinforced composite materials, ASTM editor (1982)

[7] Ch.A. Harper. Handbook of plastics elastomers and composites, (2nd ed.)McGraw-Hill, New York (1992)

[8] J. Weiss, C. Bord. Matériaux Composites, L’usine editor, Paris (1983)

[9] Santos García A. Mechanical behaviour of plaster reinforced with synthetic polymers, Doctoral Thesis. E.T.S.A.M, Polytechnic University of Madrid, 1988

[10] UNE 80301, Normas UNE Españolas para Cementos, IECA editor, 1996

[11] UNE-ENV 197-1 IN, Composición, especificaciones y criterios de conformación de los cementos comunes, AENOR editor, June, 2000 and vol. 10 - Construction, Review of UNE Standards, 1998

[12] B.R. Smith, A.E. Alexander. The effect of additives on the process of the crystallization, J Colloid Interface Sci, 34 (1976), pp. 81-90

[13] EN 83-502-88, Ensayos de Resistencia Mecánica en Hormigones, AENOR editor, 1988 (it is included the: EN-196-1 Standard. Methods of Testing of Cements. Part1: Determination of compressive strength. AENOR)

[14] J.Ma. Rincón, M. Romero. Characterization techniques of glasses and ceramics, Springer-Verlag, Heidelberg (1998)

[15] J.Ma. Rincón, M. Romero. Applications of the SEM and EPI to the glasses characterization and traditional and advanced ceramic materials, M. Aballe (Ed.) et al., Scanning electron microscopy and X-ray microanalysis, Rueda Ed, Madrid (1996), pp. 373-394

[16] R.E. Cameron. Environmental SEM principles and applications, Eur Microsc Anal (May) (1994), pp. $9-11$

[17] Stroeven P. The analysis of fibre distribution in fibre reinforced cementitious materials, Micro 76, London, 1976

[18] B.D. Barnes, S. Diamond, W.L. Dolch. Micromorphology of the interfacial zone around aggregates in Portland Cement Mortar, J Am Ceram Soc, 62 (1978), pp. 21-25

[19] H.F.W. Taylor. Studies on the chemistry and microstructure of cement pastes, Proc Brit Ceram Soc, 35 (1984), pp. 65-82

[20] J.Ma. Rincón, M. Romero, Ma .S. Hernández-Crespo, R. Talero, A. García Santos. Microestructura y propiedades mecánicas de un composite de fibras de polipropileno en matriz de cemento, MATER CONSTRUC, 54 (274) (2004), pp. 73-82 